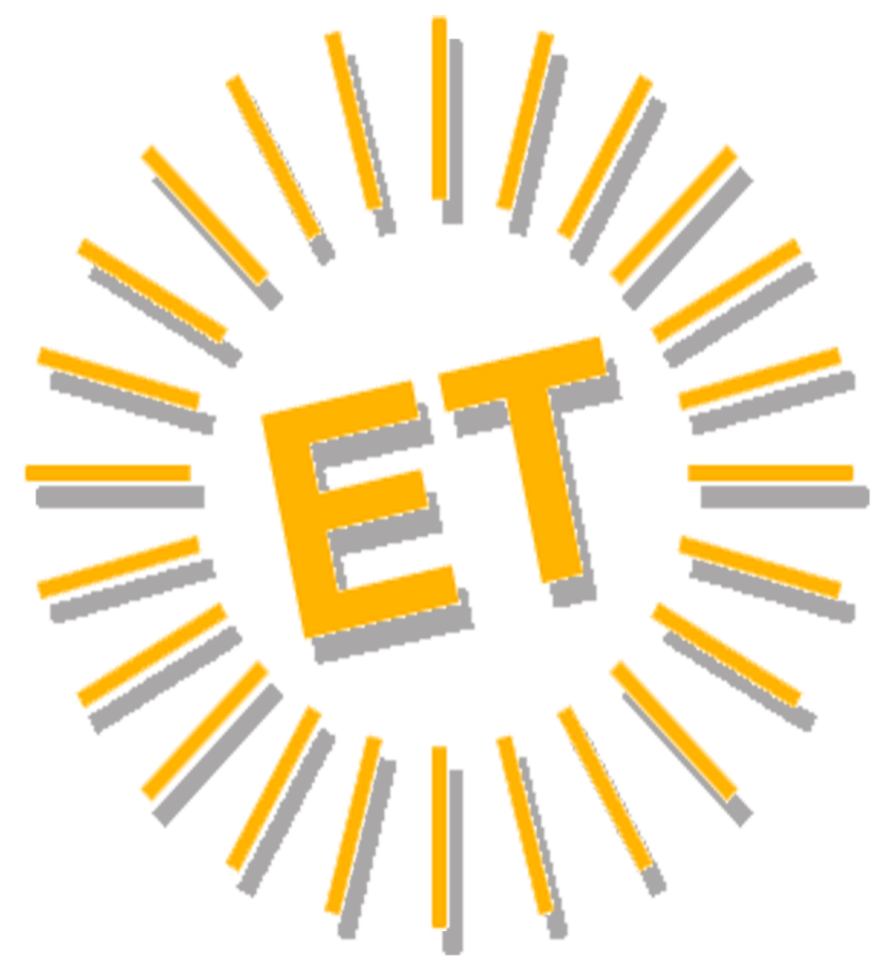




\section{Editorial Team}

Editor in Chief

Alfonso Vargas-Sánchez, University of Huelva, Spain

\section{Associate Editor}

T.C. Huan, National Chiayi University, Taiwan

\section{Books Review Editor}

Brendan Paddison, York St. John University, United Kingdom

\section{Secretariat}

Elena García de Soto, University of Huelva, Spain

Cinta Borrero-Domínguez, University of Huelva, Spain

\section{Style reviewer and text editor}

Anestis Fotiadis, I-SHOU University, Taiwan, Province of China

\section{Editorial Board}

José Manuel Alcaraz, Murdoch University, Australia Mario Castellanos-Verdugo, University of Seville, Spain José Antonio Fraiz-Brea, University of Vigo, Spain José Manuel Hernández-Mogollón, University of Extremadura, Spain

Shaul Krakover, Ben Gurion University, Israel Jean Pierre Levy-Mangin, University of Quebec, Canada Tomás López-Guzmán, University of Córdoba, Spain Yasuo Ohe, Chiba University, Japón Mirko Perano, University of Salerno, Italy María de los Ángeles Plaza-Mejía, University of Huelva, Spain Nuria Porras-Bueno, University of Huelva, Spain João Albino Silva, Algarve University, Portugal

\section{Advisory Board (Spanish Members)}

César Camisón-Zornoza, Uniersity of Valencia, Spain Enrique Claver-Cortés, University of Alicante, Spain María Teresa Fernández-Alles, University of Cádiz, Spain José Luis Galán-González, University of Seville, Spain Félix Grande-Torraleja, University of Jaén, España Antonio Leal-Millán, University of Seville, Spain Inmaculada Martín-Rojo, University of Málaga, Spain Antonio Manuel Martínez-López, University of Huelva, Spain Francisco José Martínez-López, University of Huelva, Rector, Spain

Pablo A. Muñoz-Gallego, University of Salamanca, Spain
Francisco Riquel-Ligero, University of Huelva, Spain José Miguel Rodríguez-Antón, Autonomous University of Madrid, Spain

Sandra Sanchez-Cañizares, University of Cordoba, Spain Josep Francesc Valls-Giménez, ESADE, Spain

\section{Advisory Board (Other European Members)}

Paulo Aguas, University of Algarve, Portugal Gustavo Barresi, University of Messina, Italy Carlos Costa, Aveiro University, Portugal Salvatore Esposito de Falco, University of Rome "La Sapienza", Italy

Sheila Flanagan, Dublín Institute of Technology, Ireland Tania Gorcheva, Tsenov Academy of Economics, Bulgaria Tadeja Jere-Lazanski, University of Primorska, Slovenia Metin Kozak, Mugla University, Turkey Álvaro Matias, Lusiada University, Portugal Alfonso Morvillo, National Research Council, Italy Alexandru Nedelea, Stafan cel Mare University of Suceava, Romania

Claudio Nigro, University of Foggia, Italy

Angelo Presenza, University "G. D'Annunzio" of ChietiPescara, Italy

Kanes Rajah, Royal Agricultural University, United Kingdom

\section{Advisory Board (Members from the rest of the world)}

John Allee, American University of Sharjah, United Arab Emirates

Nestor Pedro Braidot, National University of La Plata, Argentina

Roberto Elias Canese, Columbia University, Rector, Paraguay

Luca Casali, Queensland University of Technology, Australia Nimit Chowdhary, Indian Institute of Tourism and Travel Management, India

Steven Chung-chi Wu, National Pingtung University of Science and Technology, Taiwán

Dianne Dredge, Southern Cross University, Australia Daniel Fesenmaier, Temple University, United States

Babu George, Alaska Pacific University, United States Dogan Gursoy, Washington State University, United States Jafar Jafari, University of Wisconsin-Stout, United States Sanggun Lee, Pai Chai University, Korea Republic of Albert Yeh Shangpao, I-SHOU University, Taiwán Pauline Sheldon, University of Hawaii, United States Germán A. Sierra-Anaya, University of Cartagena de Indias, Rector, Colombia Xiaohua Yang, University of San Francisco, United States 


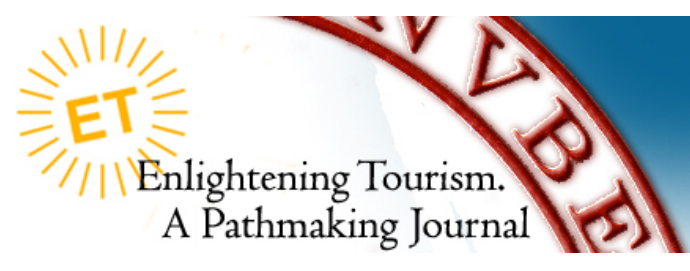

\title{
CRISIS SITUATIONS IN TOURIST DESTINATIONS: HOW CAN THEY BE MANAGED?
}

\author{
Alfonso Vargas-Sánchez \\ University of Huelva (Spain) \\ vargas@uhu.es
}

\begin{abstract}
Crisis management in tourism, whether due to natural catastrophes or to any other reason, acquires particular relevance because tourist centres are usually located in places (coasts / beaches, wooded areas, mountains, valleys of rivers,...) whose characteristics rise the potential risk, to which it is necessary to join the high densities of population if the event that triggers it (fire, torrential rain,...) takes place in periods of maximum affluence (high season). In addition, tourists are more vulnerable than residents, because of its lack of familiarity with the area and, in the case of international tourism, due to the limitations of not speaking / mastering the local language. If tourists become victims of a disaster of this type, with the added risk caused by overcrowding, the negative impact on the destination image multiplies.

Although tourism has proven to be a highly resilient activity, recovering in a relatively short time from the negative impacts of this type of events, it is no less true that managers of tourist business and destinations should not underestimate their effects.

Within this framework, and without prejudice the fact that each case is unique and therefore cannot be separated from its context, the aim of this paper is to synthesize a series of proposals that the scientific literature has revealed, as general guidelines to take into account for a proactive management of crisis situations in a tourist destination, overcoming an approach to them based on a mere reactive response.
\end{abstract}

KEYWORDS

Crisis Management; Risk Management; Proactive Management; Tourist Destinations.

ECONLIT KEYS

H12; G32; L83. 


\section{INTRODUCTION}

"For a long time, we believed that in terms of tourism, we should only 'sell' landscapes, although we are now also faced with the notion that fundamentally, we must also 'sell' safety" (Morales, 2002). In order to validate this quote, there is no better example than that which will also serve to justify the importance and potential of the chosen topic.

In Spain, the most recent and also the most paradigmatic case is that of the serious fire which occurred in the province of Huelva during the dawn of summer 2017 and which has affected Doñana Natural Park and the surrounding municipalities of Moguer and Almonte. The first was particularly affected, in addition to the coastal nucleus of Mazagón, which is very popular during the summer time and is clearly tourism oriented.

Cases like these reopen the ongoing issue regarding the management of tourism crises, which encompasses any event which has the potential to threaten the normal functioning of businesses related to tourism and harming the general reputation of a tourist destination as a result of the negative impact on the perception of its visitors. This therefore causes a decline in local economy due to the interruption in continuity of commercial operations in the local tourism and travel industry as a result of a reduction in the number of arrivals and tourist income. (Sönmez et al., 1994).

The aforementioned fire in the province of Huelva has led to such a situation, in accordance with the known consequences ${ }^{1}$. The calculations bring the surface area affected by the fire up to 8,486 hectares, in an area of significant ecological value and environmental sensitivity ${ }^{2}$, in addition to tourism.

The management of the tourism crises, albeit for reasons similar to this or others, is of particular relevance as it is common for tourist resorts to be located in areas with

\footnotetext{
${ }^{1}$ Fires and other natural disasters can destroy unique tourist resources, such as heritage of humanity which is so treasured and looked after in national parks. For example, Cioccio and Michael (2007) explain that fires in the state of Victoria, Australia, affected an area equivalent to $5 \%$ of its surface area. Tourism companies were seriously affected, with estimated losses of 20 million Australian dollars in the first month alone. The study proved the vulnerability and lack of preparation to address a danger of such a scale.

${ }^{2}$ However, a study which followed this first estimate increases the affected area to 9547 hectares: http://sevilla.abc.es/andalucia/huelva/sevi-estudio-cientifico-eleva-hectareas-impacto-incendiodonana-201707192332 noticia.html?ns campaign=rrss\&ns mchannel=abcdesevillaes\&ns source=fb\&ns linkname=seccion\&ns fee=0 [accessed 30 June 2018].
} 
an elevated risk per se (coast/beaches, wooded areas, mountains, river valleys...), to which the high population density can be added if the incident takes place during periods of maximum occupancy (high season). The fact that tourists are more vulnerable than residents as they are less familiar with the area, and in the case of international tourism, they are limited as they do not speak/have a good knowledge of the local language, also adds to this risk. If tourists fall victim to a disaster of this kind, with the additional risk of massification, the negative impact on the image of the destination itself, multiplies.

Paraskevas and Altinay (2013) highlight that due to its high interconnectivity with all societal aspects (political, economic, social, technological and environmental), the tourist destination is more vulnerable in the face of the crises and are affected by all the possible disruptions to normality, referring to political or civil disruption, natural disasters, recessions, etc., all of which may lead the tourism system to a status of chaos. According to Faulkner (2001), the root of a crisis may be seen as the incapability of organisations to face gradual or sudden changes.

Although tourism has demonstrated itself to be a highly resilient activity as it has recuperated from the negative impact of this type of event ${ }^{3}$ in a relatively short space of time, it is not less true that managers of companies and tourist destinations should not underestimate their impact: in fact, for Ritchie (2004), crisis and disaster management should be considered a basic competency in both profiles, given that as demonstrated by Burnett (1998), they are difficult to resolve due to time limitations, limited control and high levels of uncertainty.

In the case of the fire in Huelva, the news was rather widespread and not just on a national scale, given that it took place in such an important natural space: Doñana, the biggest ecological reserve in Europe and declared Heritage of Humanity by UNESCO and a Biosphere reserve, among other statuses of protection. As affirmed by Pinto Machado (2012), natural disasters often have an impact on the image of the affected destination which lasts for months, if not years. It is for this reason that media coverage of disasters and crises situations are of particular concern to managers of destinations where these disasters occur.

\footnotetext{
3 The following examples should be mentioned: United Kingdom and foot-and-mouth disease, Thailand and the South East Asian tsunami and in Spain, Galicia and the Prestige oil spill, amongst others.
} 
To summarise, tourism is therefore vulnerable to a range of crises much wider than other sectors and their occurrence tends to be more frequent. However, as a result of the nature of the sector itself, it recovers faster, becoming a driving and locomotive element of general economic recovery in the territory affected by the disaster, given its interrelation with other sectors. As we are reminded by The World Economic Forum: "efficient crisis management can make the tourism sector a catalyst for the general economic and social recuperation as a whole" (WEF, 2005).

We are therefore referring to tourism crises which are provoked by a diverse range of negative events (catastrophes) which severely alter the normal functioning of businesses and destinations and could become a serious threat to them. Classification of these events can be found in Glaesser (2003).

Those of a sudden or unforeseen nature and particularly those which have little potential to be controlled (such as the case of a forest fire), are the most prone to causing a crisis which can be further aggravated by incorrect management.

Aktas and Gunlu (2005) highlight the three elements characteristic of a crisis:

-A provocative component: the crises are the result of an unexpected event or series of events which take place over a short period of time and have the potential to cause substantial change, challenging the existing structure or even the survival of the tourist destination.

-Threat and damage: the event which gives rise to the crisis is so significant in its impact that it could pose a short-term threat to the business operations and the destination as a whole.

-Need for action: with the aim to overcome the long-term effects, the crisis requires urgent action by way of the cooperation of the main authorities and stakeholders in the sector ${ }^{4}$.

At this point, there is only scope for a reactive approach, considering the most appropriate response actions as a means by which to minimise the damage to the tourist destination (which business people have estimated, in this particular example,

\footnotetext{
${ }^{4}$ As mentioned by Ritchie (2004), there is a need for cooperation between a large number of stakeholders in order to efficiently plan and manage the crises and disasters. It requires leadership to give direction to the industry and bring the stakeholders together to facilitate the integrated management of such situations. In particular, spokespeople are required in order to efficiently deal with the media.
} 
at more than 10 million euros ${ }^{5}$ ). However, it should also be seen as an opportunity which, when managed intelligently, could facilitate a serene and constructive reflection, beyond the emergencies which come as a result of these disasters, that will enable us to learn lessons in order to improve, above all preventative action. This will enable the correction of mistakes, improvement of protocols and reaffirmation of those which worked well in order to enable a learning process to be put in place. With the institutionalisation of the corresponding mechanisms leading to the development of a preventative model for managing the crises to which the tourism sector is particularly prone, bearing in mind that each case is unique and independent and therefore cannot be separated from its context (including the socio-cultural, economic, political, physical and historical elements), which at the same time requiring the development of specific strategies.

Therefore, the objective from a management point of view would be to develop a proactive model for the management of crisis situations in a tourist destination. This research aims to contribute to the discussion by providing fundamental guidelines which should be taken into account on a generalised scale.

\section{LITERATURE CONTRIBUTIONS}

According to the Trauma, Crisis and Conflict Unit ascribed to the Faculty of Psychology at the University of Barcelona (cited by Hosteltur, 2012), the five most common errors in crisis management are the following:

1. Lack of training for the people who need to intervene. In many cases, the employees of an organisation had received theoretical training, however, without putting it into practice, in addition to the fact that they were not familiar with all the protocols which are to be put into action when the crisis or emergency were to finally occur.

2. Badly coordinated or inadequately led teams. "Generally speaking, in a crisis committee, excellent professionals who have never worked together, are brought together, and in surroundings characterised by pressure, emergencies, etc., this

\footnotetext{
${ }^{5}$ https://www.hosteltur.com/123193 incendio-moguer-origino-perdidas-10-m-sector.html [accessed 30 June 2018].
} 
does not work". Additionally, in a number of cases, the people who end up making the decisions have not even taken part in the simulations.

3. Fault in the information and communication systems. "Despite the fact that we are in the 21st century and regardless of all technological advances, it is still a common occurrence that during a crisis situation, telephones, switchboards and mobile phone lines collapse". "This is very serious and to not have emergency communication systems in place means that the individual(s) responsible for making decisions do(es) not have a complete picture of reality".

4. Very basic simulations. On a general scale, experts have detected that this type of test is too easy and in addition, they tend to plan just one or two types of simulations: for example, fires or terrorist attacks.

5. Zero learning. Both after the simulations and after a crisis or real-life emergency and despite the fact that someone prepares a series of conclusions and advice to take into account on future occasions, this type of documentation tends to be archived and is not shared nor does it "generate learning". In this respect, Blackman and Ritchie (2007) argue the important role organisational learning plays in improving the potential effectiveness of the crisis management strategies.

With regards to the latter, we can take the geographical area surrounding the aforementioned fire, known as the Aznalcóllar disaster, as an example. According to WWF/Adena (2008), the tourism sector was greatly affected by this disaster, with "a cancellation of visits which in just 1998, meant the cancellation of at least $40 \%$ of the reservations to visit the National Park. At least three years were required in order for the sector to return to acceptable statistics".

In fact, in 1998, this natural space was seriously affected by the spillage of highly polluting residues from a pyrite mine in the Sevillian area of Aznalcóllar ${ }^{6}$. When the

6 Some catastrophe taken from: http://www.ambientum.com/revista/2008/mayo/Aznalcollar.asp [accessed 30 June 2018].

This toxic spillage was 100 times bigger than that of the Prestige (six million cubic metres of acidic water compared with 63,000 tonnes of fuel).

- $\quad$ The affected area (64\% of it within the Doñana Natural Area) was equivalent to 6,482 football pitches and the volume of the comparable spillage was 630.76 times that of the Giralda tower, in the city of Seville.

The magnitude of the accident meant the unprecedented deployment in the face of an environmental disaster. The cleaning and restoration of the Guadiamar cost the Regional Government of Andalusia and the Ministry of the Environment 165,396,261 euros.

- $\quad$ A total of 868 workers collected seven million cubic metres of sludge and contaminated earth with the help of 500 cleaning trucks which collected almost 17 million kilometres (the equivalent of going around the Earth 424.16 times, along the equator. 
disaster occurred, the President of the Spanish National Research Council, César Nombela, does not believe that they have learned from the crisis management which came as a result of this disaster: "To learn the lesson would mean that in other, similar situations, they act in the first instance, without waiting for instructions from anyone, to study what is happening, make it public and propose solutions if they have already been decided upon. Unfortunately, when the Prestige sunk in autumn of 2002, four years later, they did not act in this way from the first instance". On his behalf, the ex-director of the Biological Station of Doñana, researcher Miguel Ferrer, reflects upon the actions which were taken and those which would be put into action today if a similar accident were to occur: "I thought that the occurrence in 1998 was an example that would be employed elsewhere, but that wasn't the case. Our performance was somewhat anecdotal. As it happens, scientists were not taken into account in the management of the Prestige crisis. A protocol has not been systematised. If something similar were to happen again, the crisis solution will depend exclusively on the people who have to make decisions, not on the organised response planned by the institutions. We therefore decided on the people we were given to choose from and we got it right, but we could have been mistaken"”.

As affirmed by Rodríguez-Toubes and Fraiz (2012): "When a tourist destination experiences a negative natural disaster, industrial incident, terrorist attack or epidemic, tasks which minimise the impact on the image of the destination and achieve a fast recovery should be put in place. The strategies developed by the crisis management in a tourist destination should be broad enough and global enough to be applied in different situations, without being excessively limited to concrete case studies. Additionally, they should take into consideration the preventative elements or those which anticipate a crisis, with planning being an essential part of strategic crisis management, as the preparation for a potential crisis is key for a fast and effective recovery. This proactive attitude strengthens positive aspects, such as the search for opportunities in the crisis, the improvement of the cooperation between the key

The spillage contained half of all known heavy metals in addition to a third of all chemical elements including uranium, arsenic, copper, lead, cadmium, zinc and thallium. These highly mobile elements could have entered aquifers and the food chain and were composed of small particles which could be inhaled. According to experts, this increased the overall danger level of the spillage.

${ }^{7}$ Source: http://www.ambientum.com/revista/2008/mayo/Aznalcollar.asp [accessed 30 June 2018]. 
parties and their implication and awareness to participate in the activities and different stages of crisis management".

Thus, the study by Paraskevas and Altinay (2003) demonstrated a high degree of consensus in the sense that many crises emit warning signs prior to their occurrence, however this is not true universally, as detection of signs may become a "first line of defense" for the organisation/destination. The implantation of mechanisms for the early detection or even anticipation of the crisis is, in summary, a key factor which gives crisis management a proactive dimension.

The positioning of a tourist destination as a "safe destination" is becoming more and more valued by customers, especially international customers, as a result of their increased vulnerability. This requires not only the identification of the most likely risks (forest fires, earthquakes, tsunamis, air pollution, bathing water pollution, etc.), but also the development of contingency plans which allow, if necessary, the reduction of adverse effects as far as possible, by having pre-defined action plans and their corresponding measures in place. Crisis management is therefore a strategic problem which should be managed adequately by all tourist destinations: their quality and sustainability depends on the recognition that safety (risk perception) is an essential factor in the decision made by the tourist (Law, 2006) and, therefore, its importance and that of its risks should not be underestimated.

In the words of Fink (2002), in the tourism sector, crisis management is the art of eliminating the majority of the risk and uncertainty, to which Slevitch and Sharma (2008) add that risk management is, for the most part, information handling. Consequently, all those with a responsibility in the tourism sector should learn how to adequately handle the information provided to travellers as a means by which to shape their perspective.

We are talking about disaster-induced crises, although disasters can also be fuelled or facilitated by pre-existing crises. Thus, although they are two intricately linked concepts, they must be distinguished from one another. In this sense, Faulkner (2001) considers the main distinguishing factor between a "crisis" and a "disaster" to be the extent to which the situation is attributable to the own organisation (crisis) or which originates from another source (disaster). Therefore, a crisis describes a situation that is self-inflicted as a consequence of inadequate management structures/practices, or lack of adaptation to change; while a disaster 
can be defined as a situation which is faced by a tourist destination as a consequence of sudden, catastrophic changes over which it has little or no control.

In any case, policy makers are faced with the difficult decision regarding which measures to take, as the implementation of many measures is costly and their relative effectiveness varies. The management framework we advocate will support this decision making. As stated by Rodríguez-Toubes (2010), "in order to face the situation which is the result of a disaster and to guide the overall recovery of the tourism sector, we must act systematically and interrelatedly in three areas: reconstruction, prevention and communication" ${ }^{\prime \prime}$. In this context, we believe that priority should be given to the area of prevention, as it is less developed, thus giving a proactive character to the management of this type of situation which is all the more necessary given that, as stated by Rodríguez-Toubes and Domínguez-López (2017), there is a lack of proactive crisis management models that help to reduce the damage and uncertainty.

Making the words of Rodríguez-Toubes and Fraiz (2011) our own: "the occurrence of disasters and crises will increase over time and it is therefore becoming more essential to put efficient ${ }^{9}$ crisis management measures which contribute a fast and efficient destination recovery following the crisis, into practice". This is of even more importance in the case of a sector so fragmented as that of the tourism sector, both in the business environment and public administrations with powers that affect this economic activity. This diversity complicates the response as the definition of contingency plans and coordination structures are essential, and public administrations would also be prioritised when it comes to establishing a formal crisis management framework which offers the private sector the help it requires.

As affirmed by Jia et al (2012), there are numerous ideas or theories regarding how to handle a crisis situation, although all of them, despite their difference, have

\footnotetext{
${ }^{8}$ Regarding this last aspect, it points out that "right from the start, it is of particular importance that a communication campaign is developed in order to aid recovery of the tourist destination and where possible, strengthen it".

${ }^{9}$ Blake and Sinclair (2003) found that the specific sectorial support and tax reductions are in fact the most efficient measures, and although these conclusions refer to the events which took place in the USA on 11 September, they believe it to be likely that it can also be applied to other types of crises in the tourism sector. Thus, Israeli et al (2013) highlight in their conclusions that the increased importance that the hoteliers give to government assistance in these cases, to assist with expenses and taxes; the action taken by the government is therefore a very important element in crisis management, especially when these arise as a result of external factors.
} 
some elements in common: the necessity to anticipate potential crisis situations and prepare for them; the need to provide specific information during the crisis itself; the need to react as quickly as possible and the need for long-term solutions.

In the face of a potential catastrophe, the fate of a destination cannot be left to improvisation or to fate, thinking that it will never happen to us as it is highly unlikely. In fact, "the lessons learned by the tourism industry that can then be extrapolated to other destinations in the future would be summarised as:

1. Tourism should be prepared for emergency situations with the adequate procedures $^{10}$.

2. Accurate information should always be provided, both in the first moments of the crisis and the following months.

3. The messages conveyed by international organisations such as the World Tourism Organisation (OMT) showed themselves to be very effective.

4. The public and private sectors, in addition to citizen entities, neighbours, etc., should work hand in hand" (Hosteltur, 2012).

Likewise, according to Sharpley (2005), these are the four general principles that should sustain the tourism crisis management:

1. Coordination. Crisis management must be carried out with a focus on communication, which includes local businesses, tour operators, relevant tourist organisations and even government agencies, which generally make travel recommendations.

2. Collaboration. Eliminate conflicts which may arise between different Administrations.

3. Communication. The lack of confidence by tourists and a damaged image of the destination itself may threaten the sustainability of tourism and put economic viability at risk in the long-term. Taking into account the typical negative tourist response to crisis situations, the emphasis both in the short and mid-term should be promotion and communication.

4. Commitment (predominantly in terms of levels of preparation). The thought or illusion that the crisis will not occur in our destination should be avoided and if it occurs, the impact will affect others.

\footnotetext{
${ }^{10}$ However, despite its importance, Speakman and Sharpley (2012) recognise that many tourism destinations (and businesses in the sector) continue to be unprepared for a crisis situation.
} 
Although many disasters can in fact be avoided, "the damage which they cause can be minimised and recovery sped up if the tourist destinations develop strategies according to the appropriate occurrences for this particular destination. The disaster situations require quick responses and these will only be efficient if prepared and rehearsed previously" (Faulkner, 1999). The crises begin to resolve themselves before their occurrence, thus avoiding the need for improvisation. Therefore, as highlighted by Ritchie et al (2013), the response to the catastrophic event can be carried out via the deployment of contingency plans which are already in place or via an ad momentum reactive response.

Mitroff (1988) proposed a crisis management framework which consists of five phases ("five mechanisms", in his terms): detection of signs; preparation/prevention; contention (limit damages); recovery; and learning. This model incorporates a warning sign detection mechanism to ensure better crisis preparation and also its prevention.

In order to develop the last phase referred to by Mitroff; learning, Jia et al (2012) propose a conceptual framework for knowledge management systems aimed at crises management in tourism, warning of the need for these systems based on the observation that a major challenge in crisis management is to quickly find experts with experience or specific knowledge in this type of situation. It is also clear that in a crisis scenario, communication between all the relevant stakeholders for a tourist destination and the communication of information between them is essential, to which the aforementioned systems contribute.

Another good reference point is the proposal by Wilks and Moore (2003), who present a framework for risk and crisis management in a tourist destination consisting of the four phases of the model by Heath (1998), named the 4Rs: Reduction, Readiness, Response, Recovery.

-The first signs of danger should be detected in the reduction phase ${ }^{11}$. For Paraskevas and Altinay (2013), the signs of crisis can be any type of information (qualitative or quantitative) which indicate a deviation from the norm ${ }^{12}$.

\footnotetext{
${ }^{11}$ Turner (1976), in his "Theory of Disaster Incubation", maintains that disasters are the result of multiple smaller causes, erroneous perceptions, misunderstandings and miscommunications which accumulate during an incubation period (Turner, 1994). They are signs which are generally ignored as they do not comply with the way in which safety is understood, or simply because they are warnings which come from elsewhere. Along these lines, Paraskevas and Altinay (2013) emphasise the importance of a culture of crisis across the organisation.
} 
-The preparation phase consists of crisis planning and the formation of the management team.

-In the response phase, the operations and communication plans are executed.

-Lastly, the recovery phase is oriented towards the restoration and attempts to restore normality in the destination and affected organisations.

In order for a crisis management system to be efficient, it must be consistently updated and the first two phases redefined as a preamble to the second.

Here we reinforce the words of Pforr (2006), when he argues the importance of putting proactive strategies into practice. In his opinion, governments and associations in the tourism sector ${ }^{13}$ play a leading role in the important aspects of crisis management, such as communication, information and trust in the destination. However, this role has been oriented towards a reactive line of crisis management which is insufficient. However, Ritchie (2004) warns that those responsible for tourism policy and management should move on from a reactive focus to one that is both proactive and holistic, as these are a better way of limiting the impacts of the crises.

According to Rodríguez-Toubes and Fraiz (2011): "The academic research regarding the crisis in the tourist sector have focused predominantly on the communication and promotion, however, a proactive and complete vision of crisis management in the tourism sector is required, and with even greater impact on preparation and planning. Effective strategic management of catastrophic crisis situations in tourist areas can even generate positive flows in tourism demand. Cooperation and coordination between both the institutions and agents involved appears to be the best tool that can be employed in the planning and subsequent crisis resolution.

Planning is necessary with mutual and previously agreed guidelines that should be respected by all parties involved, thus overcoming any issues with competencies. A body representing and bringing together the agents in the sector would be responsible for defining the specific plans and actions that would result from this

\footnotetext{
12 The concept of warning signs which alert of a looming crisis (or opportunity) has been widely supported in literature on general management, with diverse terminology (weak signs, early indicators, early warnings, emerging issues).

${ }^{13}$ One of Israeli et al (2011) findings suggests that the industry leaders and their government should develop a joint plan of action to deal with any future crisis situations effectively.
} 
crisis plan for tourism, adequately aligned with the sector's strategic plan. Preparation not only promotes better crisis management, but also both the integration and cohesion of the various agents and institutions in the sector and a more appropriate and active promotion policy on behalf of the bodies responsible for putting it into practice. ...

Our perception is that the businesses and destinations which have carried out prior crisis preparation find themselves in an advantageous position in terms of extraction and being able to take advantage of any opportunities which may arise".

In this sense, Pennington-Gray et al (2014) affirm that the planning of crisis management is not only good business practice, but also a way in which the destinations differentiate themselves from each other in terms of safety. For this purpose, Pinto Machado (2012) proposes a strategic focus for destination management, from proactive pre-crisis planning to the strategic implementation and finally, the evaluation and feedback.

In Chinese, the symbol for crisis consists of two symbols meaning "danger" and "opportunity". This millenary language therefore suggests that crisis also gives rise to opportunities. For example, Rodríguez-Toubes and Fraiz (2010) summarise the opportunities which arose following the Prestige oil spill which occurred on the coasts of Galicia in November 2002:

-The authorities' and society's own internal awareness of the significance of tourism in the destination. Projects of Excellence and Dynamization were carried out in areas and regions that would probably not have been put into practice, or which would have been indefinitely delayed if the disaster had not happened; permanent beach clean-up plans; support for tourism businesses affected in order to modernise and improve the qualities of their services; agreements with professional associations; improvements in infrastructure linked to tourism services and products, etc., are some of the results obtained following the crisis.

-The destination as the centre of media attention. The crisis attracted a lot of attention to the destination as it was given significant media attention, which contributed to it becoming better known in the issuing markets in addition to evoking sympathy.

-Economic aspects of the promotion. Resources were allocated in order to promote the tourist destination on behalf of the State and Autonomous Governments in amounts that had never before been reached. 
In general terms, Burnett (1998) suggests seven types of opportunities that may arise from crisis: (1) heroes are born (2) changes are accelerated (3) underlying problems are faced (4) people can be changed (5) strategies are evolved (6) early alert systems are developed (7) new competitive limits may arise.

\section{IN CONCLUSION: PROPOSALS FOR PROACTIVE TOURISM CRISIS}

\section{MANAGEMENT}

Our framework proposal would consist of a series of elements documented based on a revision of scientific literature, an inventory of experience and good practice regarding crisis management that may be considered as benchmarks in the sector and the detailed characterisation of the territory (destination) in which it is to be applied. From then on, the following phases will be covered:

1. Identification of the potential risk factors which could cause a crisis in the tourism sector.

In addition to the aforementioned contribution by Glaesser (2003), the World Economic Forum highlights three principal disaster sources (WEF, 2005):

- Environmental (for example, natural disasters such as earthquakes, floods and those provoked by man, including oil spillages and fires).

- Geopolitical (terrorism).

- $\quad$ Social (pandemics and epidemics).

Along similar lines, Luecke (2005) demonstrates a brief spectrum which highlights the source of the crises:

- Accidents and natural events.

- Health and environmental disasters.

- Product manipulation.

- Catastrophic accidents.

- Environmental damage.

- Technological faults.

- Economic force and strength of the market.

- $\quad$ Bad practice by employees.

Within this framework, peculiarities of all types (geographical, geological, climate, etc.) in the destination to which it is to be applied must be considered and the support 
of experts in each of these areas is fundamental if they are to identify and evaluate the risks to which it is exposed.

\section{Prioritisation of factors.}

The level of impact and urgency of response will be tended to according to the following scheme, with priority given to those with a high value in both aspects:

Level of impact

\begin{tabular}{|c|c|c|}
\hline High & $\begin{array}{l}\text { Analysis and tracking } \\
\text { Alternative strategies }\end{array}$ & $\begin{array}{l}\text { In depth analysis } \\
\text { Response plans }\end{array}$ \\
\hline \multirow[t]{2}{*}{ Low } & Tracking & Analysis and tracking \\
\hline & Low & High \\
\hline
\end{tabular}

Urgency of response

Source: Aaker (1987)

\section{Monitoring.}

Their monitoring is another of the pillars which form part of the model, with measures in order to obtain data regarding key indicators which could activate the application of the protocols foreseen in the contingency plans. The combination of these indicators will conform to the tourist destination dashboard and will serve as a platform for intelligent management of the crises.

\section{Execution of the contingency plans for the diverse crises contemplated.}

We would be facing the phase coined by Wilks and Moore (2003) as 'readiness'.

\section{Preparation for the response.}

This would include awareness-raising and training, the auditing and regular updating of contingency plans, the periodic verification of the availability of the means necessary for the implementation of such plans, etc. A particular mention at this point is the definition of the chain of authority or the managing entity of the tourism crisis. 
These phases will eventually shape the model to be followed. As a general reference, Faulkner (2001), in his seminal work $^{14}$, proposes the following model for disaster management in tourism.

\begin{tabular}{|c|c|c|}
\hline Phase in disaster process & $\begin{array}{l}\text { Elements of the disaster } \\
\text { management responses }\end{array}$ & $\begin{array}{l}\text { Principal ingredients of the } \\
\text { disaster management strategies }\end{array}$ \\
\hline $\begin{array}{l}\text { 1.-Pre-Event } \\
\text { When action can be taken to } \\
\text { prevent the effects of a } \\
\text { disaster. }\end{array}$ & $\begin{array}{l}\text { Precursors: } \\
\text {-Appoint a Disaster } \\
\text { Management Team Leader. } \\
\text { •Identify relevant } \\
\text { public/private sector } \\
\text { agencies/organisations } \\
\text { •Establish } \\
\text { coordination/consultative } \\
\text { framework and } \\
\text { communication systems. } \\
\text { •Develop, document and } \\
\text { communicate Disaster } \\
\text { Management Strategy. } \\
\text { •Education of industry } \\
\text { stakeholders, employees, } \\
\text { customers and community. } \\
\text { •Agreement on, and } \\
\text { commitment to, activation } \\
\text { protocols. }\end{array}$ & $\begin{array}{l}\text { Risk assessment: } \\
\text {-Assessment of potential disasters } \\
\text { and their probability of occurrence. } \\
\text {-Development of scenarios on the } \\
\text { genesis and impacts of potential } \\
\text { disasters. } \\
\text {-Develop disaster contingency } \\
\text { plans. }\end{array}$ \\
\hline $\begin{array}{l}\text { 2.-Prodroma }\left.\right|^{15} \text {. } \\
\text { When it is apparent that a } \\
\text { disaster is imminent. }\end{array}$ & $\begin{array}{l}\text { Mobilisation: } \\
\text { •Warning systems (including } \\
\text { general mass media); } \\
\text { •Establishment of a disaster } \\
\text { management command } \\
\text { centre; } \\
\text {-Safety services/equipment. }\end{array}$ & $\begin{array}{l}\text { Disaster Contingency Plans: } \\
\text {-Identify likely impacts and groups } \\
\text { at risk. } \\
\text {-Assess community and visitor } \\
\text { capabilities to cope with impacts. } \\
\text {-Articulate the objectives of } \\
\text { individual (disaster specific) }\end{array}$ \\
\hline $\begin{array}{l}\text { 3.-Emergency. } \\
\text { The effect of the disaster is } \\
\text { felt and action is necessary to } \\
\text { protect people and property. }\end{array}$ & $\begin{array}{l}\text { Action: } \\
\text { •Rescue/evacuation } \\
\text { procedures; } \\
\text { •Emergency accommodation }\end{array}$ & $\begin{array}{l}\text {-Identify actions necessary to avoid } \\
\text { or minimise impacts at each stage. } \\
\text {-Devise strategic priority (action) }\end{array}$ \\
\hline
\end{tabular}

\footnotetext{
${ }^{14}$ As recognised by Ritchie (2004), Faulkner (2001) developed the first tourism disaster management framework, which was then employed to the flooding in Katherine (Australia), with some modifications based on the application to said case (see Faulkner and Vikulov, 2001).

${ }^{15}$ The term prodromal is used in health sciences when referring to the early symptoms which are experienced prior to the manifestation of an illness.
} 


\begin{tabular}{|c|c|c|}
\hline & $\begin{array}{l}\text { and food supplies; } \\
\text {-Medical/health services; } \\
\text {-Monitoring and } \\
\text { communication systems. }\end{array}$ & $\begin{array}{l}\text { profiles for each phase. } \\
\text {-Prodromal; } \\
\text {-Emergency; }\end{array}$ \\
\hline $\begin{array}{l}\text { 4.-Intermediate: } \\
\text { A point where the short-term } \\
\text { needs of people have been } \\
\text { addressed and the main focus } \\
\text { is to return business and the } \\
\text { population to normal }\end{array}$ & $\begin{array}{l}\text { Recovery: } \\
\text {-Damage Audit/monitoring } \\
\text { systems; } \\
\text {-Clean-up and restoration. } \\
\text {-Media communication } \\
\text { strategy; }\end{array}$ & $\begin{array}{l}\text {-Long-term recovery; } \\
\text { - On-going review and revision in } \\
\text { the light of; } \\
\text {-Experience. } \\
\text {-Changes in organisational } \\
\text { structures and nersonnel. }\end{array}$ \\
\hline $\begin{array}{l}\text { 5.-Long-term (recovery): } \\
\text { Continuation of previous } \\
\text { phase, but items which } \\
\text { couldn't be attended to } \\
\text { quickly are attended to at this } \\
\text { stage. }\end{array}$ & $\begin{array}{l}\text { Reconstruction and } \\
\text { reassessment: } \\
\text {-Repair of damaged } \\
\text { infrastructure. } \\
\text {-Rehabilitation of } \\
\text { environmentally damaged } \\
\text { areas. } \\
\text {-Counselling victims. } \\
\text {-Restoration of } \\
\text { business/consumer } \\
\text { confidence and development } \\
\text { of investment plans. } \\
\text {-Debriefing to promote input } \\
\text { to revisions of learning and } \\
\text { disaster strategies. }\end{array}$ & -Changes in the environment. \\
\hline $\begin{array}{l}\text { 6.-Resolution: Routine } \\
\text { restored or new improved } \\
\text { state establishment. }\end{array}$ & Review. & \\
\hline
\end{tabular}

Source: Taken from Rodríguez-Toubes and Fraiz (2011).

Rodríguez-Toubes and Fraiz (2012) propose the following integrated management framework for tourism crises: 


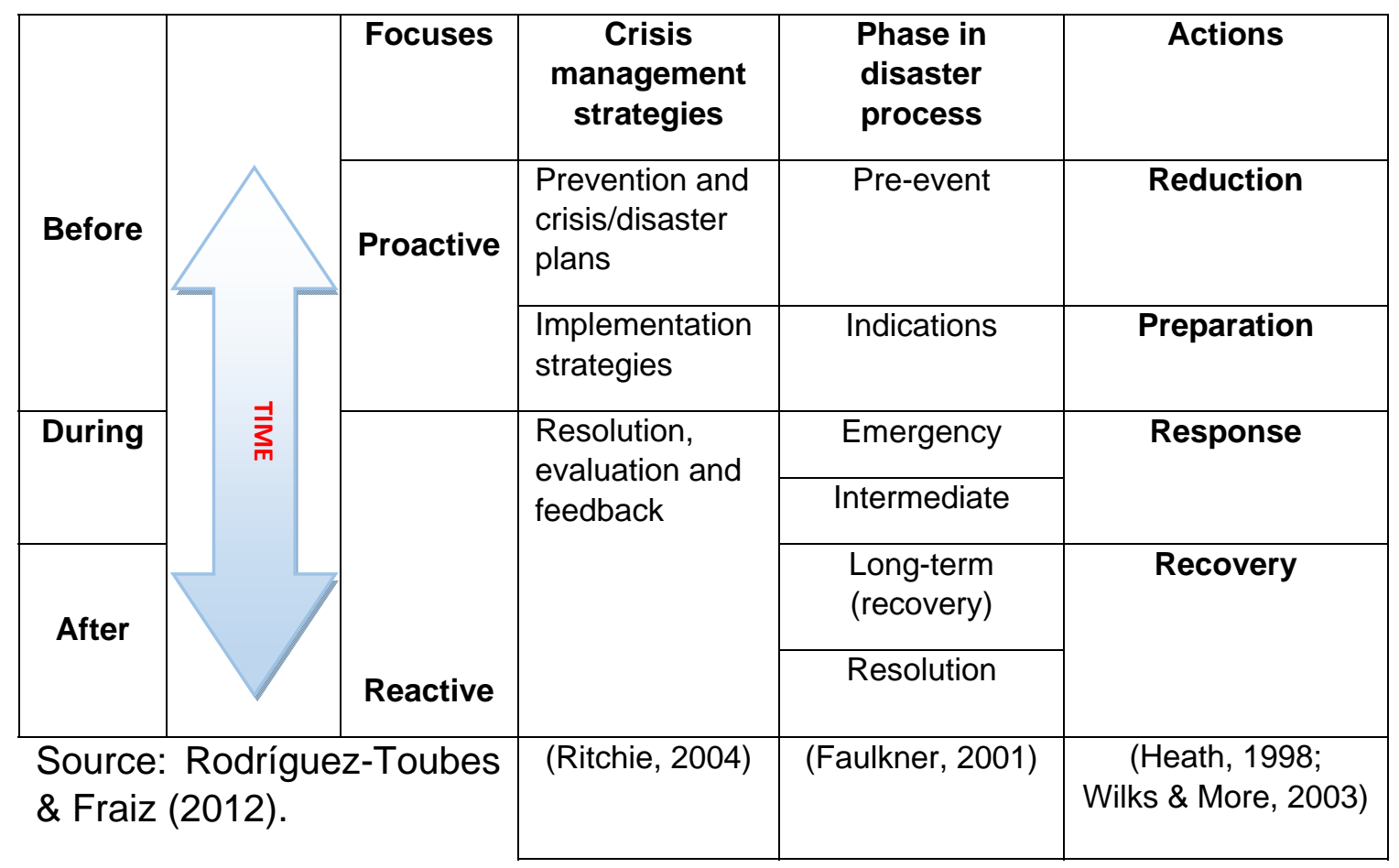

According to these authors, "the entity or organisation responsible for leading and coordinating the six phases of the framework should have sufficient authority over the tourism stakeholders, in addition to the necessary independence to confidently address the problems of resource allocation and the management of information from the indicators deployed. For this reason, the independent businesses in the sector cannot lead this process due to lack of authority and independence. At the same time, knowledge of the promotion and communication of the destination is essential when it comes to develop the planning and recover. The entity which coordinates the crisis management in the pre-impact and post-impact phases should possess knowledge of the tourism sector and the necessary implication to develop the evaluation, learning and feedback tasks, in addition to the formative activities regarding crisis management and other tasks indicated in the prevention and preparation phases" (Rodríguez-Toubes and Fraiz, 2012). In this sense, they highlight the Destination Marketing Organization (DMO) as the most suitable entities to perform these tasks, in particular the closest ones. For the same authors (Rodríguez-Toubes and Fraiz, 2014), these organisations must assume the maintenance of travellers' confidence in the safety of the destination as a priority, which inevitably entails the application of adequate management of the different types of uncertainty. 
Along the same lines, for Rodríguez-Toubes (2010), "the DMOs should play a more active role in crisis recovery, with a detailed global agenda in terms of all aspects relating to the research in crisis management, the market recovery strategies and their role in communication during the process". In fact, the tourism companies perceive the destination DMO as occupying the main role in crisis management and the posterior recovery. For this purpose, the establishment of a crisis team on behalf of the DMO is rarely specifically prepared in these aspects. Additionally, as the management of these situations does not tend to be incorporated in their strategic plans, "in the majority of cases, crisis management teams are put together at the time of the crisis" (Pike, 2004), which is a handicap.

In summary, the DMO appear to be the ideal entities for crisis communication and development of the marketing and publicity campaign in the written press, radio and television, with the aim to collaborate in the recovery efforts. The communication will have to be focused, as far as possible, on the positive aspects of the destination itself and inform the future visitors of the expected recovery time and the proposed improvements as a result of the recovery efforts (WTO and WMO, 1998). Ultimately, an important function of the DMO activity during the crisis is to serve as a source of information for the mass media, local authorities and tourism companies with the aim to ensure that the message conveyed to society, is correct, efficient and coherent with other messages which may be communicated by other local offices (RodríguezToubes, 2010).

Lastly, we can take the following words by Faulkner (2001) as an example to reinforce the need to integrate the actions: "the efficiency with which the tourism sector manages a crisis in a destination, and thus, the level of preparation, is based on the speed at which services return to normal functionality. However, the destination recovery speed basically depends on the degree to which the communication plans have been integrated with the disaster management strategies".

\section{References}

Aaker, D.A. Management Estratégico del Mercado. Barcelona: Hispano Europea, 1987. 
Aktas, G.; Gunlu, E.A. Crisis management in tourist destinations. In: W.F. Theobald (ed.), Global Tourism. Amsterdam: Elsevier, 2005, pp. 440-457.

Blake, A.; Sinclair M.T. Tourism Crisis Management. US response to September 11. Annals of Tourism Research, 30(4), 2003, pp. 813-832.

Blackman, D.; Ritchie, B.W. Tourism crisis management and organizational learning: the role of reflection in developing effective DMO crisis strategies. Journal of Travel \& Tourism Marketing, 23(2-3-4), 2007, pp. 45-57.

Burnett, J.J. A strategic approach to managing crises. Public Relations Review, 24(4), 1998, pp. 475-488.

Cioccio, L.; Michael, E.J. Hazard or disaster: Tourism management for the inevitable in Northeast Victoria. Tourism Management, 28(1), 2007, pp. 1-11.

Comisión Internacional de Expertos sobre el Desarrollo del Entorno de Doñana. Dictamen sobre Estrategias para el Desarrollo Socioeconómico Sostenible del Entorno de Doñana. Sevilla: Junta de Andalucía, 1992. Available at: http://infodigital.opandalucia.es/bvial/bitstream/10326/747/2/747.pdf [accessed 30 June 2018].

Faulkner, B. Tourism disasters: towards a generic model. Cooperative Research Centre for Sustainable Tourism. CRC Tourism work-in-progress report series, $n^{0} 6$, 1999.

Faulkner, B. Towards a framework for tourism disaster management. Tourism Management, 22(2), 2001, pp. 135-147.

Faulkner, B.; Vikulov, S. Katherine, washed out one day, back on track the next: A post mortem of a tourism disaster. Tourism Management, 22(4), 2001, pp. 331-344.

Fink, S. Crisis management: Planning for the inevitable. Cincinnati, Ohio: Backinprint, 2002.

Glaesser, D. Crisis Management in the Tourism Industry. Oxford: Elsevier Butterworth-Heinemann, 2003. 
Heath, R. Crisis Management for managers and executives. London: Pearson Education, 1998.

Hosteltur. Crisis y emergencias en turismo: lecciones recientes para no olvidar. Report, July/August 2012.

Israeli, A.A.; Mohsin, A.; Kumar, B. Hospitality crisis management practices: the case of Indian luxury hotels. International Journal of Hospitality Management, 30, 2011, pp. 367-374.

Jia, Z.; Shi, Y.; Jia, Y.; Li, D. A Framework of Knowledge Management Systems for Tourism Crisis Management. Procedia Engineering, 29, 2012, pp. 138-143.

Law, R. The perceived impact of risks on travel decisions. International Journal of Tourism Research, 8(4), 2006, pp. 289-300.

Luecke, R. Gestión de crisis. Convertirlas en oportunidades. Barcelona: Harvard Business Essential-Deusto, 2005.

Mitroff, I.I. Crisis management: cutting through the confusion. Sloan Management Review, 1988, pp. 15-20.

Morales, S. Análisis del Concepto de Seguridad Turística. Report, 2002. Available at: http://www.seguridadydefensa.com/informes/analisis-del-concepto-de-seguridadturistica-2705.html [accessed 30 June 2018].

Paraskevas, A.; Altinay, L. Signal detection as the first line of defense in tourism crisis management. Tourism Management, 34, 2013, pp. 158-171.

Pennington-Gray, L.; Schroeder, A.; Wu, B.; Donohoe, H.; Cahyanto, I. Traveler's Perceptions of Crisis Preparedness Certification in the United States. Journal of Travel Research, 53(3), 2014, pp. 353-365.

Pinto Machado, L. The consequences of natural disasters in touristic destinations: The case of Madeira Island-Portugal. Tourism and Hospitality Research, 12(1), 2012, pp. 50-56. 
Pike, S. Destination Marketing Organizations. Oxford: Elsevier, 2004.

Pforr, C. Tourism in Post-Crisis is Tourism in Pre-Crisis: A Review of the Literature on Crisis Management in Tourism. Working Paper Series, 2006-1, School of Management, Curtin University of Technology, 2006.

Ritchie, B.W. Chaos, crises and disasters: a strategic approach to crisis management in the tourism industry. Tourism Management, 25(6), 2004, pp. 669-683.

Ritchie, B.W.; Crotts, J.C.; Zehrer, A.; Volsky, G.T. Understanding the Effects of a Tourism Crisis: The Impact of the BP Oil Spill on Regional Lodging Demand. Journal of Travel Research, 53(1), 2013, pp. 12-25.

Rodríguez-Toubes, D. Comunicación institucional en el sector turístico en situaciones de crisis: estrategia de las Destination Management Organization (DMO) ante las mareas negras. Revista de Comunicación, 9, 2010, pp. 42-59.

Rodríguez-Toubes, D.; Fraiz, J.A. Gestión de crisis en el turismo: la cara emergente de la sostenibilidad. Encontros Científicos-Tourism \& Management Studies, 6, 2010, pp. 49-58.

Rodríguez-Toubes, D.; Fraiz, J.A. Gestión proactiva de crisis en el turismo: una experiencia de estudio en Galicia. Pasos, 9(2), 2011, pp. 279-289.

Rodríguez-Toubes, D.; Fraiz, J.A. Desarrollo de una política de gestión de crisis para desastres en el turismo. Tourism \& Management Studies, 8, 2012, pp. 10-18.

Rodríguez-Toubes, D.; Fraiz, J.A. Scary crises: Early perceptions of risk among fivestar tourists. International Journal of Event Management Research, 8(1), 2014, pp. 107-122.

Rodríguez-Toubes, D.; Domínguez-López, Y. Social Media in Crisis Communication: Germanwings Flight 4U9525. In: Media and Metamedia Management. Switzerland: Springer, 2017, pp. 243-249.

Sharpley, R. International tourism: the management of crisis. In: L. Pender, \& R. Sharpley (eds.). The Management of Tourism. London: Sage, 2005, pp. 275-287. 
Slevitch, L.; Sharma, A. Management of perceived risk in the context of destination choice. International Journal of Hospitality \& Tourism Administration, 9(1), 2008, pp. 85-103.

Sönmez, S.; Backman, K.; Allen, L. Managing tourism crises: A guidebook. Clemson, SC: Clemson University, 1994.

Speakman, M.; Sharpley, R. A chaos theory perspective on destination crisis management: Evidence from Mexico. Journal of Destination Marketing \& Management, 1, 2012, pp. 67-77.

Turner, B.A. The organizational and inter-organizational development of disasters. Administrative Science Quarterly, 21(3), 1976, pp. 378-397.

Turner, B.A. Causes of disaster: sloppy management. British Journal of Management, 5(3), 1994, pp. 215-219.

WEF. Disaster Response: The Tourism Dimension. Study on the Feasibility of a Global Tourism. Disaster Communication Network. Volume I: Main Report. World Economic Forum \& World Tourism Organization, 2005.

Wilks, J.; Moore, S. Tourism Risk Management for the Asia Pacific Region: An Authoritative Guide for Managing Crises and Disasters. Commonwealth of Australia, APEC International Centre for Sustainable Tourism, 2003.

WTO \& WMO. World Tourism Organization y World Meteorological Organization. Handbook on Natural Disaster Reduction in Tourist Areas. Madrid: World Tourism Organization, 1998.

WWF/Adena. La Catástrofe de Aznalcóllar. X Aniversario: ¿Una lección aprendida? Madrid: WWF/Adena, 2008. Available at: http://assets.wwf.es/downloads/ informe 2008.pdf [accessed 30 June 2018].

Article info: Received 13/02/18. Accepted 12/07/18. Refereed anonymously. 